применение богатой тромбоцитами плазмы при заболеванияк и поврендениях опорно-двигательного аппарата

\author{
М.А. Малыгина, Н.В. Боровкова, О.М. Сахарова, И.Н. Пономарев \\ ГБУЗ «НИИ скорой помощи им. Н.В. Склифосовского ДЗМ», Москва, Россия
}

Контактная инорормация: Марина Александровна Малыгина, д-р мед. наук, ведущий научный сотрудник отделения неотложной травматологии опорно-двигательного аппарата НИИ скорой помощи

им. Н.В. Склифосовского, Москва, Россия, e-mail: lapundra@ bk.ru

Дата поступления: 24.04.2017

Лечение повреждений и заболеваний опорно-двигательного аппарата непосредственно связано с применением препаратов крови. Современная жизнь заставляет совериенствовать не только методъ оперативного лечения повреждений, но и ускорять регенерацию тканей, тем самым убыстряя восстановление утраченных бункиий конечностей. Успехи трансфузиологии, а именно применение Platelet-Rich Plasma отвечают этим требованиям.

Ключевые слова: богатая тромбоцитами плазма, стимуляция остеогенеза, переломы, тендопатии

Малыгина М.А., Боровкова Н.В., Сахарова О.М., Пономарев И.Н. Применение богатой тромбоцитами плазмы при заболеваниях и повреждениях опорно-двигательного аппарата. Трансплантология. 2017;9(4):325-334. DOI:10.23873/2074-0506-2017-9-4-325-334

\title{
The use of platelet rich plasma in diseases and injuries of the musculoskeletal system
}

\section{M.A. Malygina, N.V. Borovkova, O.M. Sakharova, I.N. Ponomarev}

N.V. Sklifosovsky Research Institute for Emergency Medicine, Moscow, Russia

Correspondence to: Marina A. Malygina, Dr. Med. Sci., Leading Researcher of the Urgent Traumatology Department

for Musculoskeletal System Trauma at N.V. Sklifosovsky Research Institute for Emergency Medicine, Moscow, Russia, e-mail: lapundra@bk.ru

Received: 24 April 2017

Treatment of injuries and diseases of the musculoskeletal system is directly related to the use of blood products. Modern life makes it necessary to improve not only the surgical techniques of injury treatment, but also to accelerate tissue regeneration, thereby speeding up the recovery of lost functions in limbs. Advances in transfusion, namely the use of platelet-rich plasma, meet these requirements.

Keywords: platelet-rich plasma, stimulation of osteogenesis, fractures, tendinopathies

Malygina M.A., Borovkova N.V., Sakharova O.M., Ponomarev I.N. The use of platelet rich plasma in diseases and injuries of the musculoskeletal system. Transplantologiya. 2017;9(4):325-334. (In Russian). DOI:10.23873/2074-0506-2017-9-4-325-334

Ауто БоТП - аутоплазма, богатая тромбоцитами

БоТП - богатая тромбоцитами плазма

MKC - медиальная коллатеральная связка

BMP - bones morphogenetic protein
PRP - Platelet-Rich Plasma

PDGF $\quad$ - тромбоцитарный фрактор роста тромбоцитов

TGF- $\beta$ - трансформирующий фрактор роста

VEGF - орактор роста эндотелия сосудов
Цель: обзор посвящен результатам и перспективам использования Platelet-Rich Plasma (PRP) в лечении переломов, заболеваний и повреждений мягких тканей опорно-двигательного аппарата.
История и основные направления применения богатой тромбоцитами плазмы

История широкого использования в лечении повреждений и заболеваний опорно-двигательного аппарата различных элементов и препара- 
тов крови насчитывает несколько десятилетий. Развитие научно-технического прогресса обусловило стремительный рост хирургической активности даже в самых сложных, ранее полагавшихся инкурабельными случаях, и именно успехи современной трансфузиологии определили применение в клинической практике травматологов-ортопедов целого ряда методов клеточной терапии, в числе которых PRP, т.е. обогащенная тромбоцитами аутоплазма. В ряде работ отечественных авторов существуют аббревиатуры: БоТП - богатая тромбоцитами плазма, а также Ауто БоТП - аутоплазма, богатая тромбоцитами [1]. Встречается также такое сокращение, как OTA - обогащенная тромбоцитами аутоплазма, есть и другие варианты [2-4]. Однако в своем исследовании мы, как и большинство специалистов, придерживаемся общемировой терминологии - PRP.

Еще в середине XX века, в 1965 г. ученый из Калифорнийского университета M. Urist [5] опубликовал результаты исследования, в котором обобщил свой опыт применения PRP в качестве фрактора, способствующего увеличению количества в крови остеоиндуктивного морфогенетического белка ("bones morphogenetic protein BMP”) для стимуляции остеогенеза при дефектах костей лицевого скелета. Его работа основывалась на данных о выраженной остеогенной и хондрогенной активности пептидов, содержащихся в альфа-гранулах тромбоцитов (цит. по [4]).

Позднее предложенная методика нашла достаточно широкое применение в челюстно-лицевой хирургии, где ее применяли для улучшения качества регенерата и ускорения заживления раны имплантированных «анкеров», а также в кардиологии под названием «тромбоцитарный концентрат» или «тромбоцитарный гель» $[6,7]$. В конце XX столетия PRP использовали для лечения плохо заживающих ран при диабетической стопе, а затем при лечении одонтогенной иноекции в стоматологии и челюстно-лицевой хирургии [1, 7-9]. С начала 2000-х гг. в публикациях описано применение PRP в целях лечения переломов костей, трофических язв различной этиологии, а также в пластической хирургии и косметологии для омоложения кожи и лечения волос $[1,8]$. Впоследствии в мировой литературе появились сообщения о ее использовании и в ортопедо-травматологической практике, причем сначала в спортивной травматологии [10-13].

Среди отечественных разработок в этом направлении одной из первых работ является диссертационное исследование, завершенное в Томске в 2001 г. Ю.А. Сорокиным [14]. Автор обосновал методику внутрисуставного введения нативной аутоплазмы в количестве 12-18 мл 2-3 раза с интервалом 4-5 дней, применяемую для лечения деформирующего остеоартроза крупных суставов, и на основании проведенных клинических и морфологических исследований установил, что плазма, введенная в полость сустава, улучшает метаболические процессы и препятствует дегенерации хрящевой ткани [14].

Инъекционная форма тромбоцитарной аутоплазмы создана в 2003 г. казанскими учеными P.P. Ахмеровым и Р.Ф. Зарудий. Ими же разработаны специальные пробирки, в которых находились антикоагулянт гепарин натрия и разделительный олефиновый гель, что позволяло получать плазму с терапевтическим содержанием тромбоцитов [17]. Еще через 10 лет, в 2013 г. возглавляемый этими же учеными коллектив авторов, предложил введение PRP для лечения деформирующего остеоартроза коленных и тазобедренных суставов I-II степени тяжести. Инъекции тромбоцитарной плазмы выполняли интра- и параартикулярно по $3,5 \pm 0,5$ мл в область одного сустава с интервалом 2-3 недели, курсом 3-4 процедуры 1 раз в год. Авторы сообщили о высокой эффрективности использования $\mathrm{PRP}$, что выразилось в статистически достоверных: снижении выраженности болевого синдрома, увеличении объема движений в суставе, улучшении опорно-двигательной фрункции конечностей и удлинении периода ремиссии заболевания [17].

В 2007 г. в Курске В.Л. Брехов в своей диссертации [16], основываясь в том числе и на работах Ю.А. Сорокина, Р.Р. Ахмерова, Р.Ф. Зарудий и 3.M. Аминовой, обосновал сочетанное использование PRP в комбинации с биодеградируемыми имплантатами для оптимизации процессов регенерации костной ткани. В этом же году И.Г. Арсеньев из ЦИТО им. Н.Н. Приорова завершил исследование применения PRP в комплексном лечении переломов и ложных суставов длинных трубчатых костей, в котором обосновал высокую эфрфективность использования препарата Коллапан в сочетании с PRP: в 91,8\% случаев автор констатировал консолидацию переломов и ложных суставов, а развитие нагноительного процесса и несращение перелома наблюдались только в одном случае $(1,2 \%)$ [8].

Еще через год, в 2008 г. в ведущих отечественных журналах вышло уже несколько обзорных статей, написанных авторами из самых разных 
учреждений страны, обобщающих опыт применения PRP и ее комбинаций с различными биокомпозиционными материалами в травматолого-ортопедической практике [1]. Сейчас в доступной литературе имеются сообщения о применении PRP при лечении остеоартритов, остеоартрозов, периартритов, тендопатий сухожилий, а также при повреждениях связок и мышц [10, 17-24].

\section{Патофизиологическое обоснование использования богатой тромбоцитами плазмы при травмах и заболеваниях опорно-двигательного аппарата}

Одним из основных показаний к применению клеточных технологий, в частности именно $\mathrm{PRP}$, является возникновение так называемой остеогенной недостаточности, когда собственный камбиальный резерв костной ткани организма не в состоянии обеспечить надлежащий уровень остеорепарации $[3,7,8,17,25]$. $\mathrm{K}$ таким повреждениям в первую очередь относятся дефекты, возникающие при многооскольчатых переломах, замедленно консолидирующиеся переломы, остеоартрозы, ложные суставы длинных костей конечности, а также разрывы сухожилий и сумочно-связочного аппарата [1, 10, 20, 26-29].

По мнению многих авторов, основной составляющей замедленной консолидации и несращений переломов в первую очередь являются сама травма [28, 30-32], а именно так называемая высокоэнергетическая травма - "high energy trauma", сопровождающаяся значительным повреждением кости, мягких тканей и параоссальных структур, сочетанная или комбинированная травма, закрытые и открытые многооскольчатые переломы с малой или недостаточной площадью контакта между фрагментами, переломы, сопровождающиеся значительным посттравматическим отеком, вызывающим нарушение местного кровообращения, а также костная и мягкотканая интерпозиция [29, 33, 34].

В конце XX века установлено, что кость как высокоспециализированная ткань существует в теснейшей связи с кровеносной системой [32]. Взаимосвязь путей гемоциркуляции в костной ткани проявляется не только в местных нутритивных процессах и поддержании общего минерального равновесия внутренней среды организма, но и непосредственно в физиологической регенерации костной ткани $[7,13,31]$.
Процесс заживления перелома кости проходит три основные накладывающиеся друг на друга фразы: воспаления, репарации и ремоделирования (морфофункционального восстановления утраченных тканей) $[8,9,20,35]$. В фразу воспаления сразу после перелома вследствие разрыва сосудов костномозгового канала, кортикальной пластинки, надкостницы и прилежащих мягких тканей между концами поврежденной кости в течение 12 часов формируется гематома с развитием острого травматического воспаления и миграцией в очаг повреждения полиморфноядерных лейкоцитов, моноцитов и лимфоцитов, выделяющих провоспалительные цитокины на протяжении следующих 24-48 часов [1, 8, 17, $25,26]$. В дальнейшем происходят организация гематомы, пролиферация фрибробластов и эндотелиоцитов, а затем через 48-72 часа от момента травмы формируется грануляционная ткань. При наступлении фазы репарации выделяющиеся из элементов поврежденной кости морфогенетические белки способствуют диффреренцировке мультипотентных мезенхимальных стромальных клеток в остеобласты и хондробласты [1, 17, 36].

Развитие осложнений при лечении переломов часто обусловлено не только тяжестью повреждений, но и в значительной мере нарушениями процессов регенерации травмированных тканей, микроциркуляции, иммунодефицитными состояниями и нарушением метаболизма в организме в целом [36, 37]. При образовании воспалительных реакций в мягких тканях возникают сложные патологические изменения с поэтапным вовлечением в них всех тканевых структур, приводящие к выраженным клиническим признакам и нарушениям фрункций всего организма [17, 37].

Результаты многочисленных исследований доказали, что PRP по сути представляет из себя депо фракторов роста, а ее использование является значимой частью биотехнологий, направленных на оптимизацию процессов регенерации тканей, в том числе костной, хрящевой и мышечной, что особенно актуально, для травматологии и ортопедии [28, 38]. Исходя из этого, все перечисленные ранее состояния так или иначе служат показаниями для назначения $\mathrm{PRP}$, поскольку при них наблюдается нарушение клеточного звена гемостаза, связанное со снижением числа циркулирующих тромбоцитов или с потерей их биологической полноценности [6, 38-40].

Известно, что тромбоцит представляет собой безъядерную высокодиффреренцированную клетку с уникальными фрункциями, к которым отно- 
сятся коагулологическая, ангиотрофическая, эндотелиально-поддерживающая, транспортная и стимулирующая рост фрункции, обеспечивающие участие клетки как в воспалении, так и в репарации и регенерации [6, 7, 26, 37, 41]. При морфологическом исследовании в тромбоцитах выделяют четыре зоны: 1-я - надмембранный слой (гликокаликс); 2-я - плазматическая мембрана; 3-я - матрикс, или гель-зона; 4-я - зона органелл, содержащая уникальную систему выводящих канальцев и гранул с биологически активными веществами, синтезируемыми и выделяемыми тромбоцитами [40]. Таким образом, помимо значительной роли в регуляции гемостаза тромбоциты участвуют в регенерации тканей.

В альфа-гранулах тромбоцитов выявлено свыше 30 ростовых фракторов, из которых наиболее важное значение для регенерации костной и хрящевой тканей имеют тромбоцитарный фрактор роста тромбоцитов (PDGF), фрактор роста эндотелия сосудов (VEGF) и трансформирующий фрактор роста (TGF- $\beta$ ), представляющий собой большую группу белков. Один из них - TGF- $\beta 1$, как доказано многими специалистами по клеточным технологиям, и морфогенетические белки кости модулируют клеточную пролиферацию и дифроеренцировку малодиффреренцированных клеток в остеобласты, увеличивают синтез внеклеточного матрикса кости и ингибируют его деградацию [2, 13, 28, 42, 43]. К основным типам костных морфогенетических белков, участвующих в регуляции сращения переломов, по данным исследований, опубликованных зарубежными авторами в 2012-2014 гг., относятся: BMP2 оказывающий воздействие на образование хряща и кости и играющий основную роль в диффреренцировке остеобластов, BMP3 - действующий на образование самой кости, BMP7 - служащий основой для дифференцировки остеобластов, и BMP8а - принимающий самое активное участие в развитии кости и хряща [24, 44, 45].

В настоящее время существует множество методик изготовления PRP, и до сих пор в научном сообществе ведутся дискуссии относительно морфофризиологической и экономической целесообразности использования каждой из них. Технические аспекты получения, заготовки и хранения PRP многократно описаны в литератуpe $[2,11,18,25,28,33,37,46]$. Сотрудниками НИИ СП им. Н.В. Склифросовского также опубликованы работы, посвященные заготовке, производству и клиническому применению криоконсервированных тромбоцитов и тромбоцитарных концен- тратов [21, 26, 37-39]. В 2014 г. нашим коллегой успешно защищена диссертация (на соискание ученой степени кандидата биологических наук), которая отражает особенности морфофрунцционального статуса тромбоцитов человека в норме и патологии и представляет новый метод витального окрашивания клеток, позволяющий проводить анализ их биологической полноценности в крови, PRP и концентрате тромбоцитов [40].

На сегодняшний день применение PRP в травматологии и ортопедии является научно обоснованным методом ускорения репаративных процессов в костных, суставных и мягкотканых структурах. PRP также достаточно широко используется для лечения самых разных заболеваний и повреждений $[1,8-10,14,48]$.

Результативность технологии применения богатой тромбоцитами плазмы в лечении повреждений костей, суставов и мягких тканей различной этиологии

Использование PRP, став одним из направлений реконструктивно-восстановительного лечения различных патологических состояний опорно-двигательного аппарата, высоко оценивается большинством современных травматологов и ортопедов.

По данным изученной литературы, применение PRP с целью оптимизации процессов репаративного остео- и хондрогенеза помогло значительно улучшить результаты хирургического лечения больных с различными дефектами костной и хрящевой тканей, остеоартрозами крупных суставов [3, 4, 15, 17, 18, 33]. Многие авторы констатируют, что наиболее значимый эфрфект получен при лечении гонартроза по сравнению с другими локализациями остеоартрозов. На основании изучения результатов внутрисуставного лечения гонартроза с помощью PRP были сделаны выводы о безопасности метода, способствующего уменьшению болевых ощущений и улучшению функциональности коленного сустава в ближайшем периоде и на протяжении 6-9 месяцев с достоверным улучшением по всем оцениваемым параметрам. В целом проведенное лечение позволило в короткие сроки ликвидировать болевой синдром, улучшить функцию суставов, значимо сократить длительность болевого синдрома и увеличить длительность ремиссии [3, 9, 17, 33, 45].

Многие отечественные ученые применяли PRP при многооскольчатых и внутрисуставных переломах для адгезии свободно лежащих фррагментов 
хряща с субхондральной костью, что позволило избежать их удаления [8, 28]. Проведенные исследования доказывают положительный эффект от применения PRP в лечении повреждений мягких тканей и костей. В большинстве работ, опубликованных в 2000-2014 гг., авторы уверенно констатировали увеличение скорости образования новой кости и улучшение ее качества при использовании PRP [19, 26, 36, 43, 48]. Еще в 2004 г. R.E. Marx представил данные о качественном исследовании, посвященном применению PRP в комбинации с костным материалом, и сделал вывод о его высокой эффрективности [7]. Позднее, в 2010 г. Г.Н. Берченко и соавт. опубликовали данные о результатах изучения заживления переломов костей и о влиянии на процесс активации репаративного остеогенеза наноструктурированного материала Коллапан в сочетании с PRP. Авторы пришли к выводу о высокой эфрективности применения тромбоцитарной массы [2]. По данным исследований, осуществленных Г.А. Кесяном с соавт. (2011), использование Коллапана с PRP у пациентов с длительно несрастающимися переломами и ложными суставами длинных костей конечностей оказывает выраженное активизирующее действие на процессы остеогенеза при заживлении дефектов кости [28].

В последние несколько лет появилось много публикаций, в которых говорится о применении PRP у пациентов, подвергшихся артроскопическим вмешательствам [22, 46, 49]. В целом ряде работ рассматриваются результаты использования PRP в первую очередь на плечевом суставе в связи с травмами вращательной манжеты и при замещении дефекта манжеты мембраной, полученной из насыщенного фракторами роста аутологичного орибрина $[4,22,23,43,46]$. В большинстве оригинальных исследований и обзоров, обобщающих сведения из различных источников, говорится о высокой эфффективности методики, позволяющей существенно сократить продолжительность послеоперационного периода, снизить интенсивность болевого синдрома, ускорить репаративный процесс и улучшить качество жизни больного $[4,19,23,43,46]$. Однако в работе, вышедшей в 2016 г., R. Holtby с коллегами обследовали 92 пострадавших с повреждением вращательной манжеты плеча и не нашли данных о каких-либо серьезных различиях в подобных показателях у пациентов основной, в которой применялась методика $\mathrm{PRP}$, и контрольной групп. В исследовании получены сопоставимые результаты как непосредственно в послеопера- ционном периоде, так и через 6 месяцев и сделан вывод о необоснованности чрезмерно оптимистичных надежд на данную технологию [22].

Целый ряд исследований посвящен изучению эфрфективности применения PRP при хронических повреждениях капсульно-связочного аппарата, причем во многих из них сообщается о хороших результатах, достигнутых при лечении хронического тендиноза локтевого сустава с выраженным болевым синдромом, а также при лечении тендинопатии связки надколенника [13]. В 2003 г. S.G. Edwards и J.H. Calandruccio сообщили об эффрективности использования PRP по сравнению с результатами инъекций кортикостероидов при лечении эпикондилита [43]. Через 9 лет в 2012 г. другие исследователи - G. Filardo с коллегами описали результаты многократных введений PRP при лечении дегенеративно-дистрофических заболеваний коленного сустава после того, как предыдущее консервативное или хирургическое лечение этой патологии не дало желаемого результата, а также сделали заключение о безопасности и перспективности данной методики, поскольку у большинства пациентов наступило заметное улучшение и они смогли восстановить свою прежнюю повседневную активность [45].

По мнению многих авторов, применение PRP имеет большой потенциал при лечении повреждений боковых и крестообразных связок коленных суставов. Различные травмы медиальной коллатеральной связки (МКС) являются одними из наиболее распространенных среди активного населения планеты, и неадекватное лечение таких повреждений может приводить к раннему развитию остеоартроза [18, 19, 30, 33, 45]. В последние годы опубликованы данные об улучшении показателей максимальной нагрузки на разрыв и окончательных показателей растяжения после использования PRP при повреждении MКС и увеличении прочности связки более чем на $70 \%$ в течение 12 дней после начала применения PRP $[19,45]$. Есть публикации, в которых сообщают о многообещающих результатах использования $\mathrm{PRP}$ для лечения повреждений связок, если ее применяли в соответствующих дозах в ранние сроки после травмы [33, 45, 49].

В современной литературе представлены очень разноречивые сведения о результатах использования PRP при травмах ахиллова сухожилия. Часть специалистов утверждают, что применение методики ведет к ускорению процесса репарации, снижает отечность и болевые 
ощущения [20, 50-52]. Другие говорят о необоснованности слишком оптимистичных ожиданий и приводят сведения либо об одинаковых с контрольными группами результатах, либо даже о снижении основных показателей у групп больных, получавших лечение PRP [11, 53-55]. Однако в работе F. Karaaslan et al. сделан вывод о необходимости дальнейших исследований в этом направлении, поскольку ими были обследованы только 24 человека [35].

Боль, всегда сопровождающая любой патологический процесс или рану, одновременно субъективна по восприятию пациентом, что затрудняет объективную оценку влияния PRP на ее выраженность. В одних исследованиях показано, что у пациентов нет значительной разницы в болевых ощущениях при различном лечении $[11,55]$, в других - что при использовании PRP болевые ощущения значительно уменьшаются как по интенсивности, так и по продолжительности $[24,26,27,50]$. Так, по данным исследований A.C. Башкиной и соавт. (2011), применение PRP в купировании болевого синдрома большого вертела у женщин показало, что локальное лечение PRP превосходит по эффрективности традиционную терапию инъекциями глюкокортикостероидов. Локальная терапия с использованием PRP отличается отсутствием нежелательных реакций и высокой эффективностью при сроках наблюдения до 6 месяцев [27].

В последние 5 лет появились работы зарубежных авторов, критически оценивающие применение PRP в целом. Их скепсис отражается даже в названиях статей: "Platelet-rich plasma therapy - future or trend?” («Лечение с использованиeм PRP - будущее или тренд?»); "Platelet-rich plasma for muscle injuries: game over or time out?" («PRP при повреждениях мышц: игра окончена или перерыв?») [56, 57]. Авторы полагают методику переоцененной, но в то же время считают, что опыт, накопленный к настоящему времени, еще не достаточен для окончательных выводов.

\section{Заключение}

Лечение повреждений и заболеваний опорно-двигательного аппарата за последнее десятилетие значительно изменилось. Внедрение новых фиксаторов, бережное отношение к мягким тканям, а также использование PRP оказали значительное влияние на результаты лечения. По мнению большинства современных авторов, применение PRP - это простой, дешевый и минимально инвазивный способ получить естественную концентрацию аутологичных фракторов роста, поэтому в настоящее время широко проводятся эксперименты в различных областях медицины для выявления ее способности ускорять регенерацию ткани с низким заживляющим потенциалом, а области использования постоянно расширяются. $\mathcal{K}$ преимуществам применения PRP все ученые относят безопасность при строгом соблюдении протокола, который при разных повреждениях и заболеваниях может различаться, а также низкую себестоимость. Доступность метода и его эффрективность открывают перспективы его более широкого использования в клинической травматологии и ортопедии. 


\section{Литература}

1. Кирилова И.А., Фомичев Н.Г., Подорожная В.Т., Этитейн Ю.В. Сочетанное использование остеопластики и обогащенной тромбоцитами плазмы в травматологии и ортопедии (обзор литературы). Травматология и ортопедия России. 2008;(3):63-67.

2. Берченко Г.Н., Кесян Г.А., Микелаишвили Д.С. Применение биокомпозиционного наноструктурированного препарата Коллапан и обогащённой тромбоцитами аутоплазмы в инжиниринге костной ткани. Травма (Украина). 2010;11(1):7-14.

3. Емелин А.Л., Ахтямов И.Ф. Клиническая эффективность тромбоцитарной аутоплазмы при лечении остеоартрозов. Вестн. современной клинической медицины. 2013;6(Прил. 1):26-29.

4. Ачкасов Е.Е., Безуглов Э.Н., Ульянов А.А. и др. Применение аутоплазмы, обогащенной тромбоцитами, в клинической практике. Биомедицина. 2013;(4):46-59. 5. Urist M. Bone: formation by autoinduction. Scence. 1965;150:893-899.

6. Anitua E. Plasma rich in growth factors: Preliminary results of use in the preparation of future sites for implants. Int. J. Oral. Maxillofac. Implants. 1999;14(4):529-535. PMID:10453668

7. Marx R.E. Platelet-rich plasma: evidence to support its use. J. Oral. Maxillofac. Surg. 2004;62(4):489-496. PMID:15085519

8. Арсеньев И.Г. Экспериментально-морфологическое обоснование клинического применения деградируемых биоимплантатов в комплексном лечении переломов и ложных суставов длинных трубчатых костей: автореф. дис. ... канд. мед. наук. М., 2007. 25 с.

9. Деев Р.В., Исаев А.А., Кочиш А.Ю., Тихилов P.М. Клеточные технологии в травматологии и ортопедии: пути развития. Травматология и ортопедия России. 2008;(1):65-74.

10. Gholami M., Ravaghi H., Salehi M., et al. A systematic review and metaanalysis of the application of platelet rich plasma in sports medicine. Electron Physician. 2016;8(5):2325-2332. DOI: $10.19082 / 2325$

11. Schepull T., Kvist J., Norrman H., et al. Autologous platelets have no effect on the healing of human Achilles tendon ruptures. A randomized single-blind study. Am. J. Sports Med. 2011;39(1):3847. DOI: $10.1177 / 0363546510383515$

12. Cerza F., Carnì S., Carcangiu A., et al. Comparison Between Hyaluronic Acid and Platelet-Rich Plasma, Intra-articular Infiltration in the Treatment of Gonarthrosis. Am. J. Sports Med. 2012;40(12):2822-2827. DOI: $10.1177 / 0363546512461902$

13. Foster T.E., Puskas B.L., Mandelbaum B.R., et al. Platelet-rich plasma: from basic science to clinical applications. Am. J. Sports Med. 2009;37(11):2259-2272. DOI: $10.1177 / 0363546509349921$

14. Сорокин Ю.А. Массивные элиминации плазмы с внутрисуставным введением аутоплазмы в комплексном лечении деформирующего остеоартроза крупных суставов: автореф. дис. ... канд. мед. наук. Томск, 2001. 25 с.

15. Ахмеров Р.Р., Зарудий Р.Ф., Аминова 3.М. и др. Применение тромбоцитарной аутоплазмы при лечении гонартрозов и коксартрозов. Практическая медицина. 2013;68(2-2):17-20.

16. Брехов В.Л. Хирургическое лечение больных с дефектами костной и хрящевой ткани с применением богатой тромбоцитами аутоплазмы: дис. ... канд. мед. наук. Курск, 2007. 113 с.

17. Самодай В.Г., Рябинин С.В., Полесский М.Г., Атякшин Д.А. Возможности использования богатой тромбоцитами аутоплазмы для лечения деформирующего остеоартроза. Прикладные информационные аспекты медицины. 2015;18(3):63-67.

18. Горбатенко А.И., Костяная Н.О. Применение обогащенной тромбоцитами аутоплазмы в комплексной терапии остеоартроза коленных суставов. Вестник травматологии и ортопедии им. Н.Н. Приорова. 2016;(2):40-45.

19. Климовицкий В.Г., Соловьев И.А. Применение плазмы, обогащенной тромбоцитами, в лечении повреждений мягких и костных тканей. Травма (Украина). 2015;16(6):77-80.

20. Нахапетян Т.Г. Экспериментально-морфологическое и клиническое обоснование применения обогащенной тромбоцитами аутоплазмы при хирургическом лечении разрывов ахиллова сухожилия: автореф. дис. ... канд. мед. наук. М., 2013. 26 с.

21. Ваза А.Ю., Макаров М.С., Сластинин В.В. и др. Эффективность комбинации аллогенной богатой тромбоцитами плазмы с коллагеном при лечении дефектов бедренной кости у крыс. Трансплантология. 2016;(2):36-44.

22. Holtby R., Christakis M., Maman
E., et al. Impact of Platelet-Rich Plasma on Arthroscopic Repair of Small to Medium-Sized Rotator Cuff Tears. Orthop. J. Sports Med. 2016;4(9):1-10. DOI:10.1177/2325967116665595

23. Malavolta E.A., Gracitelli M.E., Sunada E.E., et al. Platelet-Rich Plasma in Rotator Cuff Repair. Rev. Bras. Ortop. 2015;47(6):741-747. DOI:10.1016/ S2255-4971(15)30032-X

24. Gentile P., De Angelis B., Agovino A., et al. Use of Platelet Rich Plasma and Hyaluronic Acid in the Treatment of Complications of Achilles Tendon Reconstruction. World J. Plast. Surg. 2016;5(2):124-132. PMID:27579267

25. Берченко Г.Н. Биология заживления переломов кости и влияние биокомпозиционного наноструктурированного материала Коллапан на активацию репаративного остеогенеза. Медицинский алфавит. Больница. $2011 ;(1): 12-17$.

26. Макаров М.С., Пономарев И.Н. Роль богатой тромбоцитами плазмы в репарации дефектов костной ткани. Хирургия. Журнал им. Н.И. Пирогова. $2015 ;(10): 94-99$

27. Башкина А.С., Широкова Т.С., Князева Т.С. и др. Применение обогащенной тромбоцитами плазмы в купировании болевого синдрома большого вертела. Травматология и ортопедия России. 2011(2):57-61.

28. Кесян Г.А., Берченко Г.Н., Уразгильдеев Р.З. и др. Сочетанное применение обогащенной тромбоцитами аутоплазмы и биокомпозиционного материала коллапан в комплексном лечении больных с длительно несрастающимися переломами и ложными суставами длинных костей конечностей. Вестник травматологии и ортопедии им. Н.Н. Приорова. $2011 ;(2): 26-32$.

29. Solchaga L.A., Bendele A., Shah V., et al. Comparison of the Effect of IntraTendon Applications of Recombinant Human Platelet-Derived Growth FactorBB, Platelet-Rich Plasma, Steroids in a Rat Achilles Tendon Collagenase Model. J. Orthop. Res. 2014;32(1):145-150. DOI: $10.1002 /$ jor. 22483

30. Middleton K.K., Barro V., Muller B., et al. Evaluation of the Effects of PlateletRich Plasma (PRP) Therapy Involved in the Healing of Sports-Related Soft Tissue Injuries. Iowa Orthop. J. 2012;32:150-163. PMID:23576936

31. Mazzocca A.D., McCarthy M.B., 
Chowaniec D.M., et al. Platelet-Rich Plasma Differs According to Preparation Method and Human Variability. J. Bone Joint Surg. Am. 2012;94(4):308-316. DOI:10.2106/JBJS.K.00430

32. Say F., Türkeli E., Bülbül M. Is platelet-rich plasma injection an effective choice in cases of non-union? Acta Chir Orthop. Traumatol. Cech. 2014;81(5):340345. PMID:25514343

33. Демкин С.А., Маланин Д.А., Рогова Л.Н., Демещенко М.В. Обогащенная тромбоцитами аутологичная плазма в лечении пациентов с остеоартрозом коленного сустава: современное состояние вопроса. Волгоградский научномедицинский журнал. 2013;(4):7-9.

34. Sadoghi P., Rosso C., Valderrabano V., et al. The Role of Platelets in the Treatment of Achilles Tendon Injuries. J. Orthop. Res. 2013;31(1):111-118 DOI:10.1002/jor.22199.

35. Karaaslan F., Mermerkaya M.U., Çirakli A., et al. Surgical versus conservative treatment following acute rupture of the Achilles tendon: is there a pedobarographic difference? Ther. Clin. Risk Manag. 2016;12:1311-1315. DOI:10.2147/ TCRM.S116385

36. Zhang J., Middleton K.K., Fu F.H., et al. HGF Mediates the Anti-inflammatory Effects of PRP on Injured Tendons. PLoS One. 2013;8(6):e67303. DOI:10.1371/journal.pone.0067303

37. Оболенский В.Н., Ермолова Д.А., Макаров М.С. и др. Стимуляция регенераторных процессов в хронических ранах с помощью богатой тромбоцитами аутоплазмы: клинико-экспериментальное исследование. Клиническая и экспериментальная хирургия 2016 ;(1):38-43.

38. Хубутия М.Ш., Высочин И.В., Кобзева Е.Н. и др. Производство и клиническое применение криоконсервированных тромбоцитов и тромбоцитных концентратов. Вестник службы крови России. 2015;(3):45-51.

39. Макаров М.С., Кобзева Е.Н., Высочин И.В. Биологическая полноценность и клиническая эффективность крио- консервированных тромбоцитов человека. Молодой ученый. 2016;(2):357-360. 40. Макаров M.C. Особенности морфофункционального статуса тромбоцитов человека в норме и патологии: авторефр. дис. ... канд. биол. наук. М., 2014. 24 с.

41. Zavadil D.P., Satterlee C.C., Costigan J.M., et al. Autologous Platelet Gel and Platelet-Poor Plasma Reduce Pain With Total Shoulder Arthroplasty. J. Extra Corpor. Technol. 2007;39(3):177-182.

42. Aspenberg P. Stimulation of tendon repair: mechanical loading, GDFs and platelets. A mini-review. Int. Orthop. 2007;31(6):783-789.

43. Edwards S.G., Calandruccio J.H Autologous blood injections for refractory lateral epicondylitis. Am. J. Hand Surg. 2003;28(2):272-278. DOI:10.1053/ jhsu.2003.50041

44. Hamid M.S.A., Mohamed Ali R.M., Yusof A., George J. Platelet-rich plasma (PRP): an adjuvant to hasten hamstring muscle recovery. A randomized controlled trial protocol (ISCRTN66528592): Study protocol. BMC Musculoskelet Disord. 2012;13:138. DOI:10.1186/14712474-13-138

45. Filardo G., Kon E., Di Martino A., et al. Platelet-rich plasma vs hyaluronic acid to treat knee degenerative pathology: study design and preliminary results of a randomized controlled trial. BMC Musculoskelet Disord. 2012;13:229. DOI:10.1186/1471-2474-13-229

46. Carr A., Cooper C., Murphy R., et al. PARot - assessing platelet-rich plasma plus arthroscopic subacromial decompression in the treatment of rotator cuff tendinopathy: study protocol for a randomized controlled trial. Trials. 2013;14:167. DOI:10.1186/1745-6215-14167

47. Cole B.J., Seroyer Sh.T., Filardo G. et al. Platelet-Rich Plasma: Where Are We Now and Where Are We Going? Sports Health. 2010;2(3):203-210. DOI: $10.1177 / 1941738110366385$

48. Nourissata G., Mainardb D., Kelberinec F. Current concept for the use of PRP in arthroscopic surgery.
Orthop. Traumatol. Surg. Res. 2013;99(8, Suppl.):S407-S410. DOI:10.1016/j. otsr.2013.10.010

49. Chen L., Liu J.P., Tang K.L., et al. Tendon Derived Stem Cells Promote Platelet-Rich Plasma Healing in CollagenaseInduced Rat Achilles Tendinopathy. Cell Physiol. Biochem. 2014;34(6):2153-2168. DOI:10.1159/000369659

50. Filardo G., Kon E., Di Matteo B., et al. Platelet-rich plasma injections for the treatment of refractory Achilles tendinopathy: results at 4 years. Blood Transfus. 2014;12(4):533-540. DOI: $10.2450 / 2014.0289-13$

51. Chen L., Dong S.W., Liu J.P., et al. Synergy of Tendon Stem Cells and Platelet-Rich Plasma in Tendon Healing. J. Orthop. Res. 2012;30(6):991-997. DOI: $10.1002 /$ jor. 22033

52. Cervelli V., Gentile P., Brinci L., et al. Use of platelet rich plasma (PRP) and hyaluronic acid in treatment of extremity gunshot injuries: a case report. World J. Plast. Surg. 2016;5(1):80-84. PMID:27308248

53. de Vos R.J., Weir A., Tol J.L., et al. No effects of PRP on ultrasonographic tendon structure and neovascularisation in chronic midportion Achilles tendinopathy. Br J Sports Med. 2011;45(5):387-392. DOI: $10.1136 /$ bjsm.2010.076398

54. Shapiro A.D. Platelet Function Disorders. Treatment of Hemophilia Monograph Series. World Federation of Hemophilia: 1999. N.19. 297p.

55. Xie X., Zhang C., Tuan R.S. Biology of platelet-rich plasma and its clinical application in cartilage repair. BMC Arthritis Res. Ther. 2014;16(1):204. DOI: $10.1186 / \operatorname{ar} 4493$

56. Dhillon R.S., Schwarz E.M., Maloney M.D. Platelet-rich plasma therapy future or trend? BMC Arthritis Res. Ther. 2012;14(4):219. DOI:10.1186/ar3914 57. Mosca M.J., Rodeo S.A. Platelet-rich plasma for muscle injuries: game over or time out? Curr. Rev. Musculoskelet. Med. 2015;8(2):145-153. DOI:10.1007/s12178$015-9259-\mathrm{x}$ 


\section{References}

1. Kirilova I.A., Fomichev N.G., Podorozhnaya V.T., Etiteyn Yu.V. Combined use of osteoplasty and platelet-enriched plasma in traumatology and orthopedics (literature review). Traumatology and Orthopedics of Russia. 2008;(3):63-67. (In Russian)

2. Berchenko G.N., Kesyan G.A., Mikelaishvili D.S. Application of the biocomposite nanostructured preparation Collapan and enriched platelets of autoplasma in the engineering of bone tissue. Trauma (Ukraine). 2010;11(1):7-14. (In Russian). 3. Emelin A.L., Akhtyamov I.F. Clinical efficacy of platelet autoplasma in the treatment of osteoarthritis. The Bulletin of Contemporary Clinical Medicine. 2013;6(Suppl 1):26-29. (In Russian).

4. Achkasov E.E., Bezuglov E.N., Ul'yanov A.A., et al. Application platelet-rich plasma in clinical practice. Biomedicine. 2013;(4):46-59. (In Russian).

5. Urist M. Bone: formation by autoinduction. Scence. 1965;150:893-899.

6. Anitua E. Plasma rich in growth factors: Preliminary results of use in the preparation of future sites for implants. Int $J$ Oral Maxillofac Implants. 1999;14(4):529-535. PMID: 10453668

7. Marx R.E. Platelet-rich plasma: evidence to support its use. J Oral Maxillofac Surg. 2004;62(4):489-496. PMID:15085519

8. Arsen'ev I.G. Experimental-morphological substantiation of clinical application of degradable bioimplants in complex treatment of fractures and false joints of long tubular bones: Cand. med. sci. diss. Synopsis. Moscow, 2007. 25 p. (In Russian).

9. Deev R.V., Isaev A.A., Kochish A.Yu., Tikhilov R.M. Cell technologies in traumatology and orthopedics: ways of development. Traumatology and Orthopedics of Russia. 2008;(1):65-74. (In Russian). 10. Gholami M., Ravaghi H., Salehi M., et al. A systematic review and metaanalysis of the application of platelet rich plasma in sports medicine. Electron Physician. 2016;8(5):2325-2332. DOI: $10.19082 / 2325$

11. Schepull T., Kvist J., Norrman H., et al. Autologous platelets have no effect on the healing of human Achilles tendon ruptures. A randomized single-blind study. Am J Sports Med. 2011;39(1):3847. DOI: $10.1177 / 0363546510383515$

12. Cerza F., Carnì S., Carcangiu A., et al. Comparison Between Hyal- uronic Acid and Platelet-Rich Plasma, Intra-articular Infiltration in the Treatment of Gonarthrosis. Am $J$ Sports Med. 2012;40(12):2822-2827. DOI: $10.1177 / 0363546512461902$

13. Foster T.E., Puskas B.L., Mandelbaum B.R., et al. Platelet-rich plasma: from basic science to clinical applications. Am J Sports Med. 2009;37(11):2259-2272. DOI: $10.1177 / 0363546509349921$

14. Sorokin Yu.A. Massive plasma elimination with intraarticular autoplasm in the complex treatment of deforming osteoarthritis of large joints: Cand. med. sci. diss. Synopsis. Tomsk, 2001. 25 p. (In Russian).

15. Samoday V.G., Ryabinin S.V., Polesskiy M.G., Atyakshin D.A. The possibility of using of platelet-rich autoplasma in osteoarthritis treatment. Applied and IT Research in Medicine. 2015;18(3):63-67. (In Russian).

16. Akhmerov R.R., Zarudiy R.F., Aminova Z.M., et al. Use of thrombocytic autoplasma in treatment of gonarthrosis and coxarthrosis. Practical medicine. 2013;68(2-2):17-20. (In Russian).

17. Brekhov V.L. Surgical treatment of patients with bone and cartilage defects with the use of platelet-rich autoplasm: Cand. med. sci. diss. Kursk, 2007. 113 p. (In Russian)

18. Gorbatenko A.I., Kostyanaya N.O. Use of PlateletRich Autoplasma in Complex Therapy of Knee Osteoarthrosis. Vestnik travmatologii $i$ ortopedii imeni N.N. Priorova. 2016;(2):40-45. (In Russian).

19. Klimovitskiy V.G., Solov'ev I.A. The use of plasma enriched with platelets in the treatment of soft and bone damage. Trauma (Ukraine). 2015;16(6):77-80. (In Russian)

20. Nakhapetyan T.G. Experimentalmorphological and clinical substantiation of the use of platelet-enriched autoplasma during surgical treatment of the Achilles tendon ruptures: Cand. med. sci. diss. Synopsis. Moscow, 2013. 26 p. (In Russian)

21. Vaza A.Yu., Makarov M.S., Slastinin V.V., et al. Efficiency of allogenic platelet-rich plasma, combined with collagen, in rat's humerus injury healing. Transplantologiya. 2016;(2):36-44. (In Russian). 22. Holtby R., Christakis M., Maman E., et al. Impact of Platelet-Rich Plasma on Arthroscopic Repair of Small to Medium-Sized Rotator Cuff Tears. Orthop J Sports Med. 2016;4(9):1-10.
DOI: $10.1177 / 2325967116665595$

23. Malavolta E.A., Gracitelli M.E., Sunada E.E., et al. Platelet-Rich Plasma in Rotator Cuff Repair. Rev Bras Ortop. 2015;47(6):741-747. DOI:10.1016/ S2255-4971(15)30032-X

24. Gentile P., De Angelis B., Agovino A., et al. Use of Platelet Rich Plasma and Hyaluronic Acid in the Treatment of Complications of Achilles Tendon Reconstruction. World J Plast Surg. 2016;5(2):124-132. PMID:27579267

25. Berchenko G.N. Biology of healing of bone fractures and the effect of the biocomposite nanostructured material Collapan on activation of reparative osteogenesis. Medical alphabet. Hospital. 2011;(1):12-17. (In Russian).

26. Makarov M.S., Ponomarev I.N. Platelet rich plasma in bones defects regeneration. Khirurgiya. Zhurnal imeni N.I. Pirogova. 2015;(10):94-99. (In Russian). 27. Bashkina A.S., Shirokova T.S., Knyazeva T.S., et al. Application of platelet-rich plasma in reduction of greater trochanteric pain syndrome. Traumatology and Orthopedics of Russia. 2011(2):57-61. DOI:10.21823/2311-29052011-0-2-57-61 (In Russian).

28. Kesyan G.A., Berchenko G.N., Urazgil'deev R.Z., et al. Combined application of platelet-enriched autoplasm and biocomposite material collapan in the complex treatment of patients with long-terminating fractures and false joints of long limb bones. Vestnik travmatologii $i$ ortopedii imeni N.N. Priorova. 2011;(2):26-32. (In Russian).

29. Solchaga L.A., Bendele A., Shah V., et al. Comparison of the Effect of IntraTendon Applications of Recombinant Human Platelet-Derived Growth Factor-BB, Platelet-Rich Plasma, Steroids in a Rat Achilles Tendon Collagenase Model. J Orthop Res. 2014;32(1):145-150. DOI: $10.1002 /$ jor.22483

30. Middleton K.K., Barro V., Muller B., et al. Evaluation of the Effects of PlateletRich Plasma (PRP) Therapy Involved in the Healing of Sports-Related Soft Tissue Injuries. Iowa Orthop J. 2012;32:150163. PMID:23576936

31. Mazzocca A.D., McCarthy M.B., Chowaniec D.M., et al. Platelet-Rich Plasma Differs According to Preparation Method and Human Variability. $J$ Bone Joint Surg Am. 2012;94(4):308-316. DOI:10.2106/JBJS.K.00430

32. Say F., Türkeli E., Bülbül M. Is plate- 
let-rich plasma injection an effective choice in cases of non-union? Acta Chir Orthop Traumatol Cech. 2014;81(5):340345. PMID:25514343

33. Demkin S.A., Malanin D.A., Rogova L.N., Demeshchenko M.V. Treatment of knee degeneration with prp intra-articular injections: current state of the issue. Volgograd journal of medical research. 2013;(4):7-9. (In Russian).

34. Sadoghi P., Rosso C., Valderrabano V., et al. The Role of Platelets in the Treatment of Achilles Tendon Injuries. J Orthop Res. 2013;31(1):111-118. DOI:10.1002/jor.22199

35. Karaaslan F., Mermerkaya M.U., Çirakli A., et al. Surgical versus conservative treatment following acute rupture of the Achilles tendon: is there a pedobarographic difference? Ther Clin Risk Manag. 2016;12:1311-1315. DOI:10.2147/ TCRM.S116385

36. Zhang J., Middleton K.K., Fu F.H., et al. HGF Mediates the Anti-inflammatory Effects of PRP on Injured Tendons. PLoS One. 2013;8(6):e67303. DOI:10.1371/journal.pone.0067303

37. Obolenskiy V.N., Ermolova D.A., Makarov M.S., et al. Clinical and experimental study: stimulation of regenerative processes in chronic wounds using platelets rich autoplasma. Clinical and Experimental Surgery. Petrovsky journal. 2016;(1):38-43. (In Russian).

38. Khubutiya M.Sh., Vysochin I.V., Kobzeva E.N., et al. Preparation and clinical administration of the cryopreservation platelets and platelets concentrates. Vestnik sluzhby krovi Rossii. 2015;(3):4551. (In Russian).

39. Makarov M.S., Kobzeva E.N., Vysochin I.V. Biological integrity and clinic efficiency of cryopreserved human platelets. Young Scientist. 2016;(2):357-360. (In Russian).

40. Makarov M.S. Features of the morphofunctional status of human platelets in the norm and pathology: Cand. biol. sci. diss. Synopsis. Moscow, 2014. 24 p.
(In Russian).

41. Zavadil D.P., Satterlee C.C., Costigan J.M., et al. Autologous Platelet Gel and Platelet-Poor Plasma Reduce Pain With Total Shoulder Arthroplasty. J Extra Corpor Technol. 2007;39(3):177-182.

42. Aspenberg P. Stimulation of tendon repair: mechanical loading, GDFs and platelets. A mini-review. Int Orthop. 2007;31(6):783-789.

43. Edwards S.G., Calandruccio J.H Autologous blood injections for refractory lateral epicondylitis. Am J Hand Surg. 2003;28(2):272-278. DOI:10.1053/ jhsu.2003.50041

44. Hamid M.S.A., Mohamed Ali R.M., Yusof A., George J. Platelet-rich plasma (PRP): an adjuvant to hasten hamstring muscle recovery. A randomized controlled trial protocol (ISCRTN66528592): Study protocol. BMC Musculoskelet Disord. 2012;13:138. DOI:10.1186/1471-247413-138

45. Filardo G., Kon E., Di Martino A., et al. Platelet-rich plasma vs hyaluronic acid to treat knee degenerative pathology: study design and preliminary results of a randomized controlled trial BMC Musculoskelet Disord. 2012;13:229 DOI:10.1186/1471-2474-13-229

46. Carr A., Cooper S., Murphy R., et al. PARot - assessing platelet-rich plasma plus arthroscopic subacromial decompression in the treatment of rotator cuff tendinopathy: study protocol for a randomized controlled trial. Trials. 2013;14:167. DOI:10.1186/1745-6215-14167

47. Cole B.J., Seroyer Sh.T., Filardo G., et al. Platelet-Rich Plasma: Where Are We Now and Where Are We Going? Sports Health. 2010;2(3):203-210. DOI: $10.1177 / 1941738110366385$

48. Nourissata G., Mainardb D., Kelberinec F. Current concept for the use of PRP in arthroscopic surgery. Orthop Traumatol Surg Res. 2013;99(8 Suppl):S407-S410. DOI:10.1016/j. otsr.2013.10.010
49. Chen L., Liu J.P., Tang K.L., et al. Tendon Derived Stem Cells Promote Platelet-Rich Plasma Healing in Collagenase-Induced Rat Achilles Tendinopathy. Cell Physiol Biochem. 2014;34(6):21532168. DOI: $10.1159 / 000369659$

50. Filardo G., Kon E., Di Matteo B. et al. Platelet-rich plasma injections for the treatment of refractory Achilles tendinopathy: results at 4 years. Blood Transfus. 2014;12(4):533-540. DOI: $10.2450 / 2014.0289-13$

51. Chen L., Dong S.W., Liu J.P., et al. Synergy of Tendon Stem Cells and Platelet-Rich Plasma in Tendon Healing. J Orthop Res. 2012;30(6):991-997. DOI: $10.1002 /$ jor.22033

52. Cervelli V., Gentile P., Brinci L., et al. Use of platelet rich plasma (PRP) and hyaluronic acid in treatment of extremity gunshot injuries: a case report. World J Plast Surg. 2016;5(1):80-84 PMID:27308248

53. de Vos R.J., Weir A., Tol J.L., et al. No effects of PRP on ultrasonographic tendon structure and neovascularisation in chronic midportion Achilles tendinopathy. Br J Sports Med. 2011;45(5):387-392. DOI:10.1136/bjsm.2010.076398.

54. Shapiro A.D. Platelet Function Disorders. Treatment of Hemophilia Monograph Series. World Federation of Hemophilia: 1999. N. 19. 297 p.

55. Xie X., Zhang C., Tuan R.S. Biology of platelet-rich plasma and its clinical application in cartilage repair. BMC Arthritis Res Ther. 2014;16(1):204. DOI:10.1186/ ar4493

56. Dhillon R.S., Schwarz E.M., Maloney M.D. Platelet-rich plasma therapy future or trend? BMC Arthritis Res Ther. 2012;14(4):219. DOI:10.1186/ar3914

57. Mosca M.J., Rodeo S.A. Platelet-rich plasma for muscle injuries: game over or time out? Curr Rev Musculoskelet Med. 2015;8(2):145-153. DOI:10.1007/s12178$015-9259-\mathrm{x}$ 